\title{
Trichostatin A induces bladder cancer cell death via intrinsic apoptosis at the early phase and Sp1-survivin downregulation at the late phase of treatment
}

\author{
SHOU-CHIEH WANG ${ }^{1,2^{*}}$, SHOU-TSUNG WANG ${ }^{2,3^{*}},{\text { HUNG-TE } \text { LIU }^{3}, \text { XIANG-YU WANG }}^{3}$, \\ SHE-CHING WU ${ }^{2}$, LEI-CHIN CHEN ${ }^{4}$ and YI-WEN LIU ${ }^{3}$ \\ ${ }^{1}$ Division of Nephrology, Department of Internal Medicine, Kuang Tien General Hospital, \\ Taichung 433, Taiwan, R.O.C.; Departments of ${ }^{2}$ Food Science and ${ }^{3}$ Microbiology, Immunology and \\ Biopharmaceuticals, National Chiayi University, Chiayi 600, Taiwan, R.O.C.; ${ }^{4}$ Department of Nutrition, \\ I-Shou University, Jiaosu Village, Yanchao District, Kaohsiung 82445, Taiwan, R.O.C.
}

Received December 24, 2016; Accepted June 27, 2017

DOI: 10.3892/or.2017.5795

\begin{abstract}
Histone deacetylase (HDAC) inhibitors have been widely shown to result in cancer cell death. The present study investigated the mechanisms underlying the antitumor effects of the phytochemical trichostatin A (TSA), a classic pan-HDAC inhibitor, in 5,637 urinary bladder cancer cells. It was found that TSA caused cell cycle arrest at the G2/M and G1 phase accompanied by reduced expression of cyclin D1 and upregulated induction of p21. In addition, TSA induced morphological changes, reduced cell viability and apoptotic cell death in 5,637 cells through caspase-3 activation followed by PARP cleavage. The loss of mitochondrial membrane potential (MMP) indicated that TSA induced apoptosis in 5,637 cells through the intrinsic mitochondrial pathway. TSA significantly suppressed Akt activity at $12 \mathrm{~h}$ after treatment, suggesting that the apoptosis in the early phase was mediated by Akt inhibition. In addition, the protein level of transcription factor Sp1 was decreased at $24 \mathrm{~h}$ after TSA treatment, which
\end{abstract}

Correspondence to: Professor Yi-Wen Liu, Department of Microbiology, Immunology and Biopharmaceuticals, National Chiayi University, 300 Syuefu Road, Chiayi 600, Taiwan, R.O.C.

E-mail: ywlss@mail.ncyu.edu.tw

Professor Lei-Chin Chen, Department of Nutrition, I-Shou University, 8 Yida Road, Jiaosu Village, Yanchao District, Kaohsiung 82445, Taiwan, R.O.C.

E-mail: lcchen@isu.edu.tw

Abbreviations: TSA, trichostatin A; CDKI, cyclin-dependent kinase inhibitor; MMP, mitochondrial membrane potential; MPTP, mitochondrial permeability transition pore; HDAC, histone deacetylase; PARP, poly(ADP-ribose) polymerase; Sp1, specificity protein 1; IAP, inhibitor of apoptosis

*Contributed equally

Key words: Akt, apoptosis, trichostatin A, urinary bladder cancer, Sp1, survivin likely led to the downregulation of survivin gene expression, and then contributed to the antitumor activity of TSA. Taken together, the present study delineated that TSA-induced growth inhibition and apoptosis in 5,637 cells was associated with pAKT inhibition and MMP loss at the early phase, followed by downregulation of $\mathrm{Sp} 1$ and survivin at the late phase of treatment.

\section{Introduction}

Bladder cancer is the 9th leading cause of cancer-related deaths with $\sim 430,000$ new cases (3.1\% of total) and accounts for $\sim 16,500$ deaths worldwide annually $(1,2)$. Notably, it is notorious for the high rate of local recurrence $(\sim 70 \%)$; thus, additional surgical resection is repeatedly required for patients even during their entire life (3). In fact, it is reported that bladder cancer is the most expensive human cancer to treat based on the cumulative/patient cost from diagnosis until death (4). For this reason, there is an urgent need to develop novel treatment strategies to counteract such a tenacious disease.

Histone acetylases and histone deacetylases (HDACs) play opposing activities in the acetylated level of histones resulting in various degrees of gene expression. Remarkably, the HDAC-induced extensive deacetylated level of histones has been linked to carcinogenesis by suppressing the expression of tumor regulatory genes, such as p21(WAF/CIP1) (5). In contrast, HDAC inhibitors may reverse this process by blocking HDAC activity leading to the re-expression of silenced regulatory genes $(6,7)$, thereby inducing cytotoxicity in cancer cells and acting as a potential new class of anticancer agents $(7,8)$. In addition, HDAC inhibitors have recently been noted for their ability to activate not only histones, but also nonhistone substrates in diverse cellular responses, including cell cycle arrest, differentiation, apoptosis and altering metastasis in numerous cancer cell types (9). A plethora of structurally diverse HDAC inhibitors have been identified (10) and some of them have exhibited demonstrable antitumor activity and have a favorable safety profile in clinical studies (11). To date, four HDAC inhibitors are approved by the United States Food 
and Drug Administration (US FDA) (12), including suberoylanilide hydroxamic acid (SAHA), romidepsin (FK-228), belinostat (PXD-101) and panobinostat (LBH-589) for the treatment of lymphoma or multiple myeloma.

Trichostatin A (TSA), a hydroxamic acid-derived phytochemical that originally serves as an antifungal antibiotic, is a classic pan-HDAC inhibitor selectively repressing the class I and II HDAC families of enzymes at nanomolar concentrations (13). Despite the expensive production and toxicity in clinical trials, TSA is now mainly regarded as a prototype compound with great potency to be a useful reference tool for further investigation of new HDAC inhibitors (14). TSA has been widely reported to induce cell cycle arrest $(15,16)$, promote apoptosis $(17,18)$, and suppress angiogenesis $(19,20)$ or metastasis $(21,22)$ in various types of tumors. However, the precise molecular mechanisms underlying the antitumor actions in urothelial carcinoma (UC) have not been fully delineated. Therefore, in the present study, we aimed to elucidate how TSA regulates the related apoptotic pathways by targeting 5,637 bladder cancer cells. Furthermore, the presented implications found between TSA and UC may provide essential evidence not only in the identification of therapeutic targets, but also further for effective antitumor drug development.

\section{Materials and methods}

Cell culture. The 5,637 urothelial cell line, a grade II carcinoma, was purchased from the Bioresource Collection and Research Center (Hsinchu, Taiwan). The 5,637 cells were maintained in RPMI-1640 medium (Gibco Life Technologies, Grand Island, NY, USA) supplemented with $10 \%$ fetal bovine serum (FBS; Biological Industries, M.P. Ashrat, Israel), $1.5 \mathrm{~g} / 1$ sodium bicarbonate, $4.5 \mathrm{~g} / 1 \mathrm{D}$-glucose, $1 \%$ penicillin-streptomycin (Gibco Life Technologies), $1 \mathrm{mM}$ sodium pyruvate and $10 \mathrm{mM}$ HEPES. Cells were plated on $100-\mathrm{mm}$ plastic dishes and incubated in a $\mathrm{CO}_{2}$ incubator at $37^{\circ} \mathrm{C}$, with $5 \% \mathrm{CO}_{2}$ and $95 \%$ filtered air.

Cell viability assay. Cell viability was determined using a colorimetric 3-(4,5-dimethylthiazol-2-yl)-2,5-diphenyltetrazolium bromide (MTT) assay. The cells were seeded in 96-well plates at a density of $4 \times 10^{3}$ cells/well for $24 \mathrm{~h}$, and then were incubated with various concentrations of test agents for another 12-36 h. MTT was added into the medium at $37^{\circ} \mathrm{C}$ for $2 \mathrm{~h}$, and the medium was then discarded and dimethyl sulfoxide (DMSO) was added to dissolve the formazan product. Each well was measured by light absorbance at $540 \mathrm{~nm}$. The result was expressed as the percentage of the normal saline-treated control group.

Cell cycle analysis. Firstly, $1 \times 10^{6}$ cells were seeded in 100-mm dishes for a 24-h incubation. Afterwards, TSA or sterile alcohol was added for another 12 and $24 \mathrm{~h}$ of treatment. The cells were then harvested, centrifuged at $800 \mathrm{x}$ g for $5 \mathrm{~min}$ and fixed with ice-cold $75 \%$ ethanol overnight at $4^{\circ} \mathrm{C}$. Following removal of the ethanol, the cells were stained with a DNA staining solution [containing $1 \mathrm{mg} / \mathrm{ml}$ propidium iodide (PI) and $10 \mathrm{mg} / \mathrm{ml}$ RNase A dissolved in phosphate-buffered saline (PBS)] for $30 \mathrm{~min}$ at room temperature. The relative DNA content of the stained cells was measured using a FACScan flow cytometer (BD Biosciences, San Jose, CA, USA). The cell doublets were removed by gating the left area of the FL2-W vs. FL2-A dot plot for analysis. The cell cycle data from flow cytometry were analyzed using ModFit LT ${ }^{\mathrm{TM}}$ software (Verity Inc., Sunnyvale, CA, USA).

Annexin V-FITC and PI staining. Apoptotic cells were also detected using Annexin $\mathrm{V}$ labeling. Cells were treated as above and harvested, and then stained with $2 \mu \mathrm{l}$ Annexin V-FITC and $2 \mu \mathrm{l}$ PI staining solution (Bio-Genesis Technologies, Inc., Taipei, Taiwan) in the dark at room temperature for $15 \mathrm{~min}$. The cell samples were immediately analyzed by the same flow cytometry and software program as previously mentioned.

Measurement of mitochondrial membrane potential (MMP, $\Delta \Psi \mathrm{m})$. The fluorescence intensity of Rhodamine 123 (Sigma-Aldrich, St. Louis, MO, USA), which is permeable to the mitochondrial membrane then specifically quenched in the mitochondria due to the MMP, was used as a measure of membrane damage. In brief, $5 \times 10^{5}$ cells were incubated with $5 \mu \mathrm{M}$ Rhodamine 123 for $10 \mathrm{~min}$ at $37^{\circ} \mathrm{C}$. The cells were then centrifuged at $200 \mathrm{x} \mathrm{g}$ for $6 \mathrm{~min}$, resuspended in PBS, and kept on ice in the dark. The staining intensity was determined using the FACS analysis $(E x / E m=485 / 535 \mathrm{~nm})$ as previously mentioned. Negative staining for Rhodamine 123 represented the loss of $\Delta \Psi \mathrm{m}$.

Western blot analysis. Briefly, the TSA-treated and control cells were washed with PBS and incubated for $20 \mathrm{~min}$ in $150 \mu$ of lysis buffer containing PRO-PREP ${ }^{\mathrm{TM}}$ protein extraction solution (iNtRON Biotechnology, Gyeonggi-do, Korea), $0.1 \mathrm{M} \mathrm{NaF}$ and $0.5 \mathrm{M}$ vanadate. The mixture was centrifuged at $12,000 \mathrm{x} \mathrm{g}$ for $5 \mathrm{~min}$, and then the total protein extract in the supernatant fluid was collected and aliquoted for $30 \mu \mathrm{g}$ for further analysis. Protein concentrations were determined using the Pierce BCA assay kit (Thermo Scientific, Rockford, IL, USA). For immunoblotting, proteins on the analytical $10 \%$ SDS-PAGE gels were transferred to a polyvinylidene difluoride membrane using a trans-blot apparatus. Antibodies against cleaved caspase-3, caspase-9, PARP, survivin (Cell Signaling Technology, Inc., Danvers, USA), $\alpha$-tubulin, GAPDH, $\beta$-actin (GeneTex, Irvine, CA, USA), p-Akt, cyclin D1, p21 (Santa Cruz Biotechnology, Paso Robles, CA, USA) and Sp1 (Upstate Biotechnology, Lake Placid, NY, USA) were used as the primary antibodies. Mouse, rabbit or goat $\operatorname{IgG}$ antibodies conjugated to horseradish peroxidase were used as the secondary antibodies. An enhanced chemiluminescence kit and Chemi-Smart 3000 system (Vilber Lourmat Corporation, Torcy, France) were used for detection, and the quantity of each band was determined using MultiGauge software (Fujifilm, Tokyo, Japan).

Statistical analysis. Numerical data are expressed as the mean \pm standard error from triplicate experiments. Statistical differences were analyzed using one-way analysis of variance analysis followed by Student's t-test. All statistics were calculated using SigmaPlot version 12.5 (Systat Software, Inc., San Jose, CA, USA).

\section{Results}

TSA alters cell morphology and significantly reduces cell viability. TSA is a very toxic chemical in 5,637 cells. As shown 
A

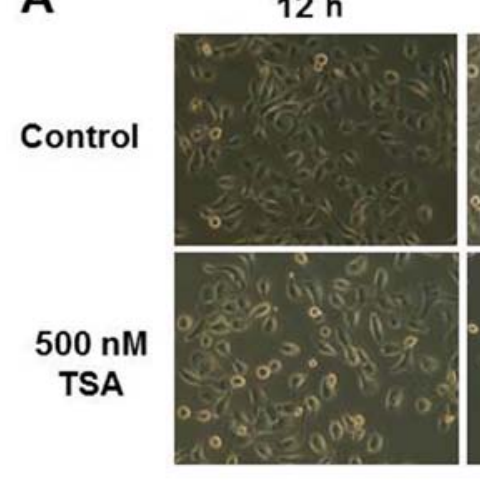

$24 \mathrm{~h}$

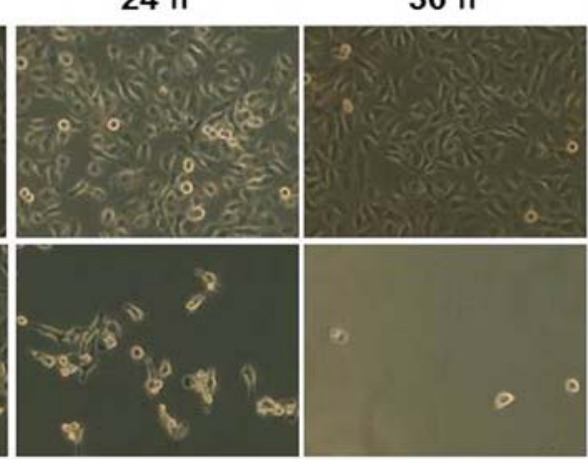

B

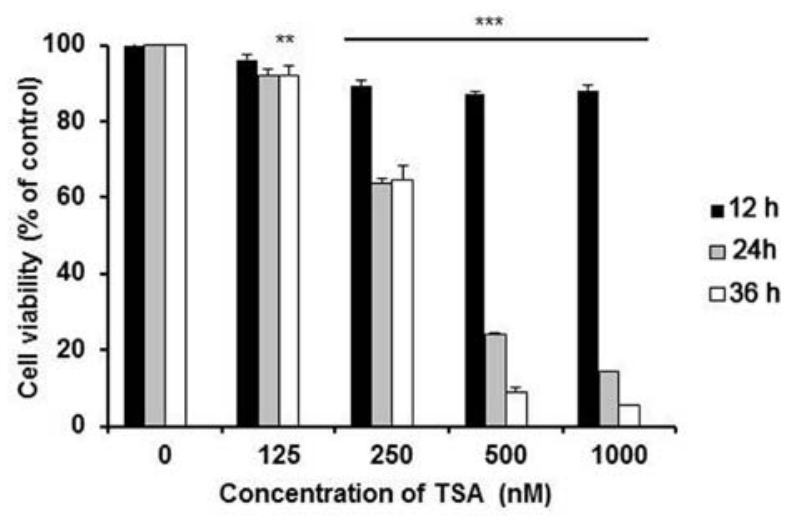

Figure 1. Cytotoxicity of TSA in 5,637 cells. (A) TSA induced an alteration in cell morphology. (B) Cell viability analysis following TSA treatment; ** $<<0.01$, **** $<0.001$.

in Fig. 1A, the 5,637 cells in the normal culture exhibited a spindle-shaped morphology. After exposure to $500 \mathrm{nM}$ TSA for $12 \mathrm{~h}$, some cells rounded up. After $24 \mathrm{~h},>70 \%$ of the cells rounded up and the attached cells showed marked change to an elongated shape with filamentous protrusions. The viability of the 5,637 cells was then assessed using MTT assay. The 5,637 cells treated with TSA displayed decreased cell viability in a dose-dependent manner after $24 \mathrm{~h}$ (Fig. 1B). Furthermore, it was found that most of the cells died after co-culture with $500 \mathrm{nM}$ TSA for $36 \mathrm{~h}$, which was also well reflected in the markedly low cell viability presented here. Since the $\mathrm{IC}_{50}$ value of TSA was determined between 250 and $500 \mathrm{nM}$ after a 24-h treatment, these concentrations were used in the following experiments.

TSA causes cell cycle arrest of the 5,637 cells. HDAC inhibitors have been reported to cause growth arrest at the G1 and G2/M phases in a wide variety of tumor cells (23). To elucidate whether TSA induces growth arrest in 5,637 cells, flow cytometric analysis was used. We measured cell cycle distribution at 12 and $24 \mathrm{~h}$, respectively, after treatment with varying concentrations of TSA $(125,250$ and $500 \mathrm{nM})$. The results showed that $\mathrm{G} 2 / \mathrm{M}$ arrest and the sub-G1 portion were formatted along with the rising concentration of TSA at $12 \mathrm{~h}$. At $24 \mathrm{~h}$, there was a moderate increase in $\mathrm{G} 1$ phase portion at a lower dosage (125 and $250 \mathrm{nM})$, while a large degree of cell death was correlated with enhanced sub-G1 phase cells observed under a high dosage (500 nM) of TSA (Fig. 2A). Since p21 is the principal cyclin-dependent kinase inhibitor (CDKI) involved in cell cycle arrest upon DNA damage (24), we analyzed p21 expression by western blotting following TSA treatments. As shown in Fig. 2B, p21 expression was significantly increased in a dose-dependent manner following a 12-h treatment. In contrast, cyclin D1 was correspondingly found downregulated following both a 12- and 24-h treatment (Fig. 2B). These findings demonstrated that TSA may regulate $\mathrm{G} 2 / \mathrm{M}$ and $\mathrm{G} 1$ phase arrest by modulating both $\mathrm{p} 21$ and cyclin D1 expression in 5,637 cells. Due to the rationale that HDAC inhibitors may regulate gene expression, the p21 mRNA expression level was then detected to verify whether TSA has an effect on p21 mRNA. However, as shown in Fig. 2C, the amount of p21 mRNA did not change following TSA treatment, suggesting that an alternative pathway was attributable to the enhanced $\mathrm{p} 21$ protein accumulation rather than the direct transcriptional activation of TSA.

TSA induces cell death via apoptosis in 5,637 cells. Based on the evidence from the cell cycle assay that TSA induced severe death of 5,637 cells, we next examined the apoptosis status using Annexin V-PI staining in cells exposed again to four varying concentrations of TSA for 12 and $24 \mathrm{~h}$. As shown in Fig. 3A, TSA caused dose-dependent apoptosis based on an increase in the number of Annexin V-positive cells at $12 \mathrm{~h}$ and at $24 \mathrm{~h}$ (UR, late apoptosis). In addition, apoptosis was further confirmed by the evidence of cleaved PARP and cleaved caspase-3 as detected by western blotting (Fig. 3B). In essence, the cell viability was restored when the pan-caspase inhibitor Z-VAD-FMK was applied (Fig. 3C), suggesting that TSA-induced cell death was mediated by the caspasedependent apoptotic pathway. 
A

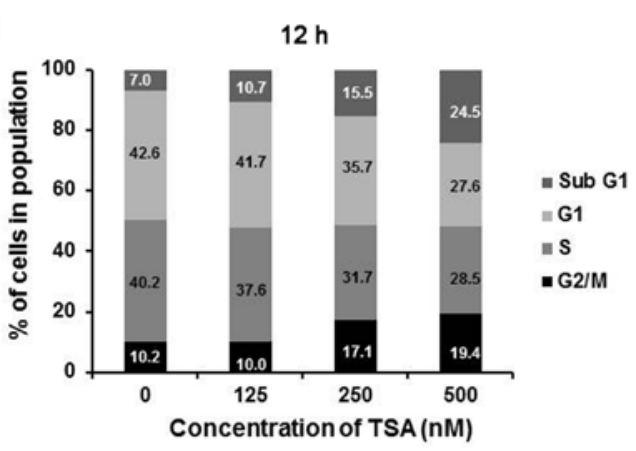

$24 \mathrm{~h}$

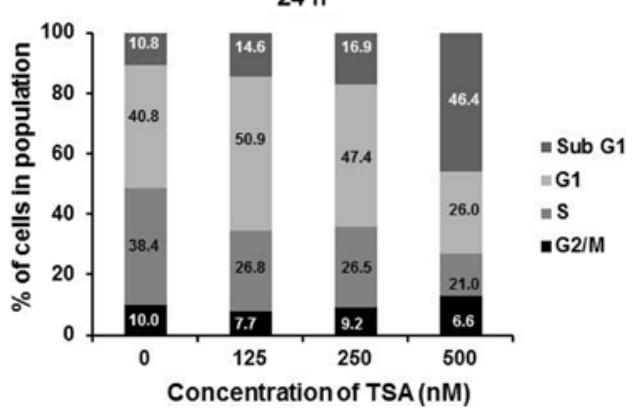

B

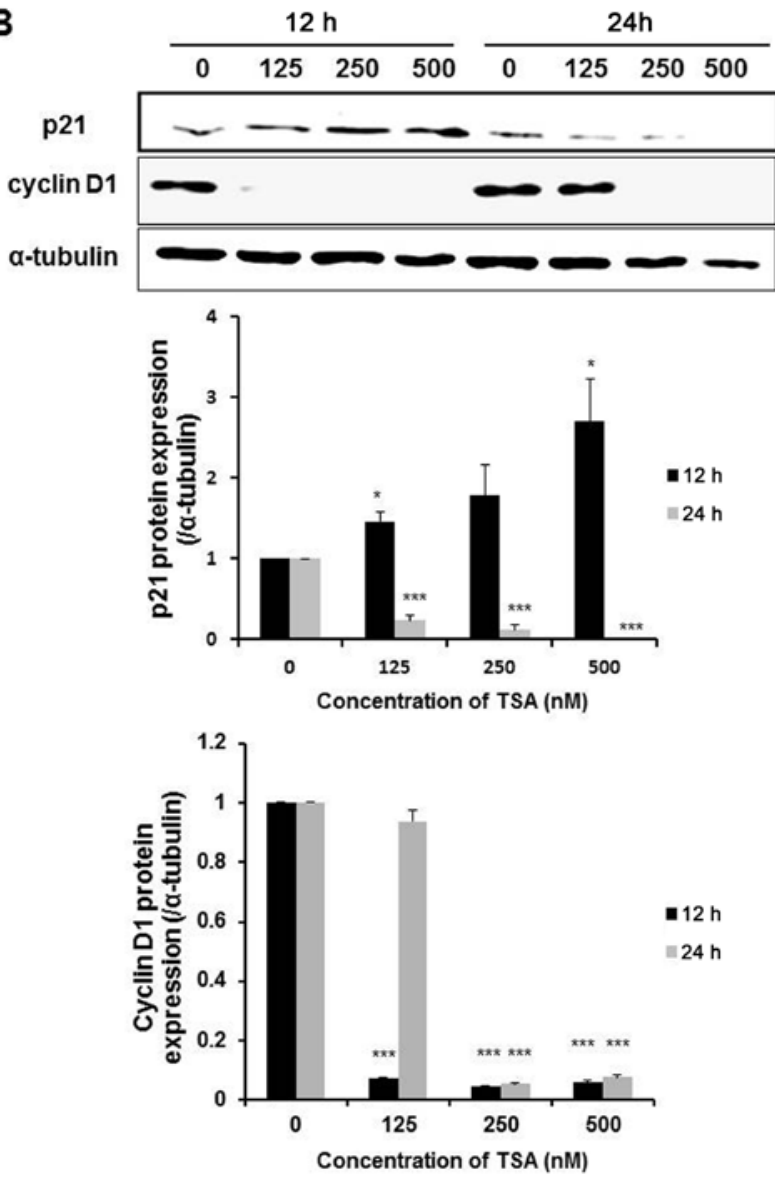

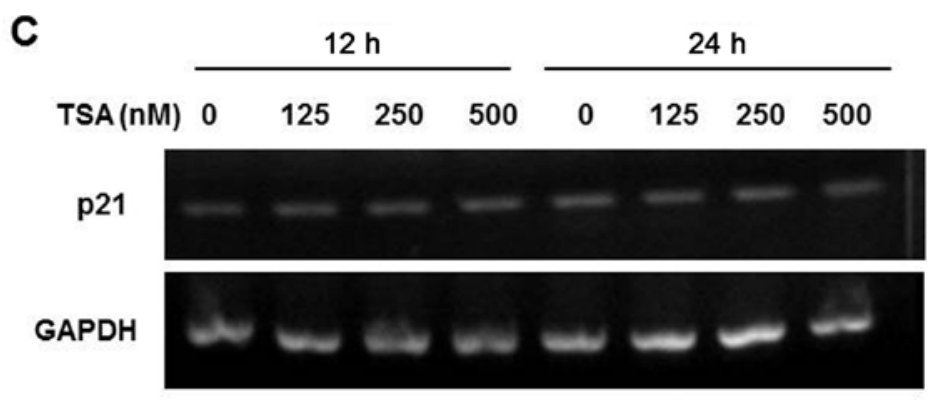

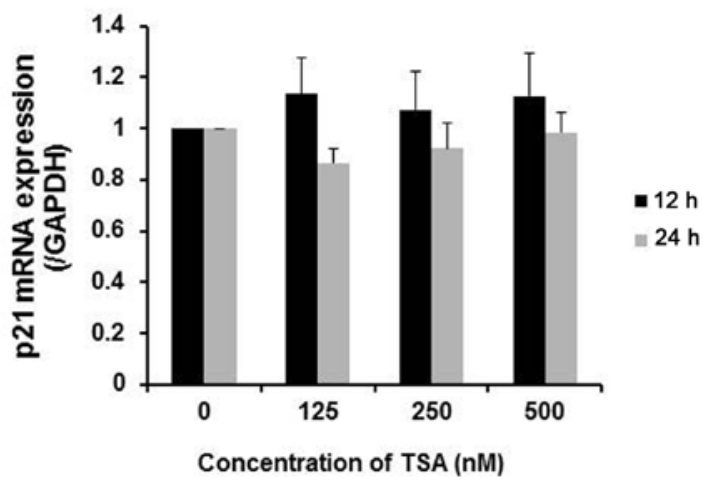

Figure 2. TSA induces cell cycle arrest and a change in protein expression of p21 and cyclin D1. (A) TSA induced G1 arrest in 5,637 cells. (B) Change in protein expression of p21 and cyclin D1 after TSA treatment. (C) mRNA level of p21 did not change following TSA treatment; ${ }^{*}$ p $<0.05$, ${ }^{* * *}$ p $<0.001$.

TSA induces apoptosis in 5,637 cells via the mitochondrial pathway by causing MMP dissipation and caspase-9 activation. The progression of apoptosis has been closely related to the injury suffered from MMP collapse (25). Since the TSA-induced apoptotic clues come from the activation of intrinsic pathway, subsequently we measured the change in MMP to assess whether the apoptosis process was associated with irreversible mitochondrial depolarization. In the present 
A

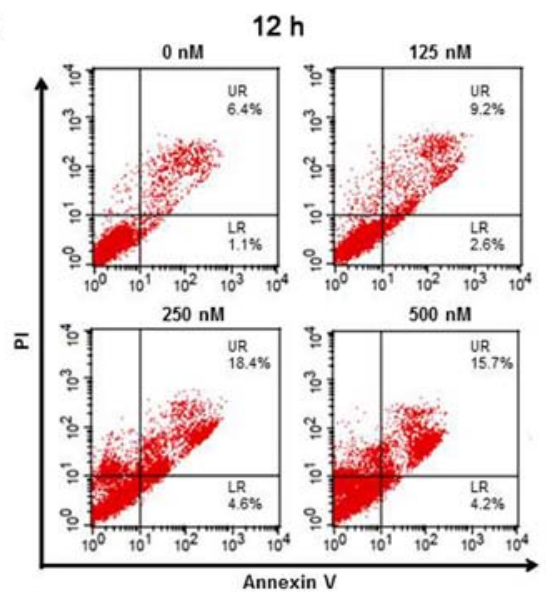

$24 \mathrm{~h}$

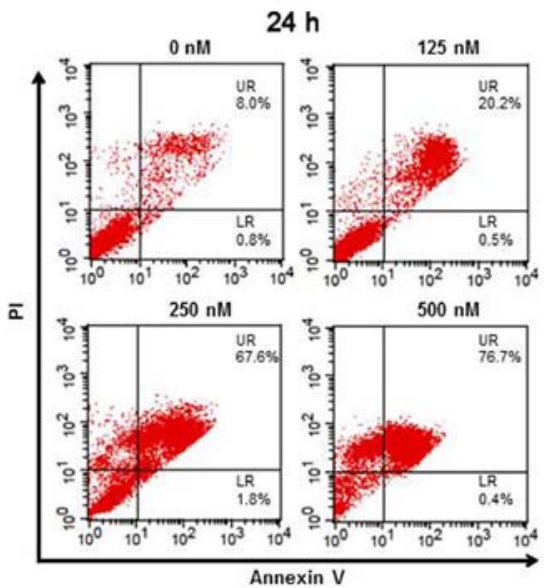

B
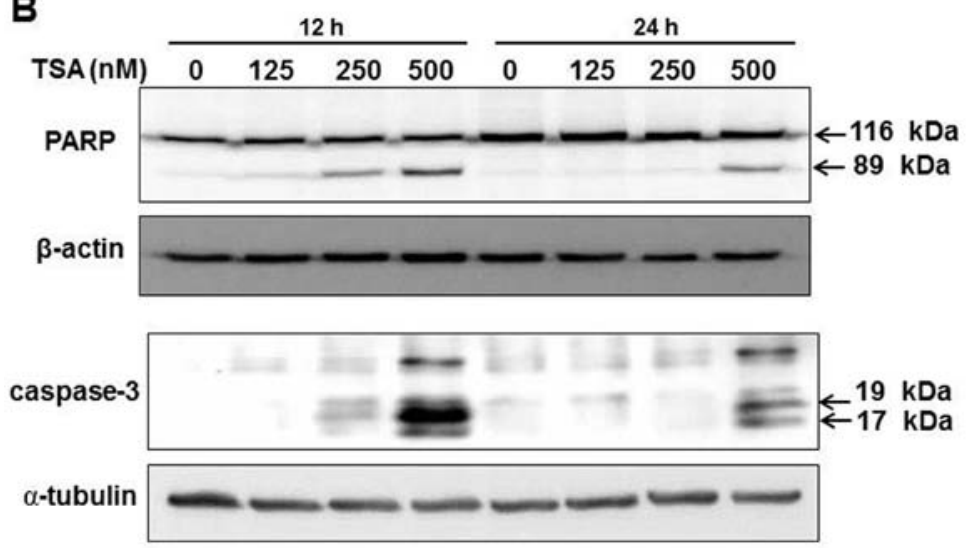

C

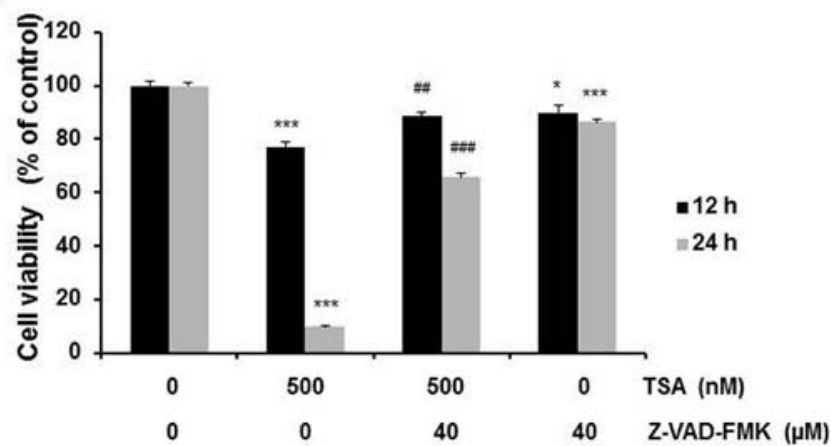

Figure 3. TSA induces apoptotic cell death. (A) Flow cytometric analysis of Annexin V and propidium iodide (PI) staining following TSA treatment. (B) TSA induced cleavage of PARP and pro-caspase-3. (C) Pan-caspase inhibitor Z-VAD-FMK reversed TSA-induced cell death; ${ }^{*} \mathrm{p}<0.05,{ }^{* * * *} \mathrm{p}<0.001$ in comparison with the control group; ${ }^{\# \#} \mathrm{p}<0.01,{ }^{\# \#} \mathrm{p}<0.001$ in comparison with the group administered TSA alone.

study, the loss of MMP in TSA-treated 5,637 cells was determined by use of Rhodamine 123 dye via flow cytometric assay. As shown in Fig. 4A, the loss of MMP was noted in the histograms, in which a clear peak shift was shown along with the increasing TSA concentration, indicating that TSA could lead to depolarization of the inner mitochondrial membrane in a dose-dependent manner. The percentage of the cells with mitochondrial depolarization was $13.6,14.9$ and $16.1 \%$ in response to 125,250 and $500 \mathrm{nM}$ of TSA treatment at $12 \mathrm{~h}$, and 27.4, 50.8 and $77.8 \%$ at 24 h, respectively. Furthermore, the downstream apoptotic effector caspase- 9 was also demonstrated to be activated accompanied by the MMP loss (Fig. 4B). Collectively, these observations strongly support the notion that TSA-induced apoptosis in 5,637 cells occurred through the intrinsic mitochondrial pathway.

TSA suppresses the PI3K-Akt signaling pathway in 5,637 cells. Previously published data explored in various cancer cell studies have indicated a role for PI3K/Akt in the cytotoxocity of TSA $(26,27)$. We next examined whether the PI3k-Akt signaling pathway may also contribute to TSA-induced apoptosis in 5,637 cells. As shown in Fig. 5A, TSA dose-dependently reduced Akt phosphorylation (ser473) after $12 \mathrm{~h}$ of treatment. While at $24 \mathrm{~h}$, only $500 \mathrm{nM}$ TSA suppressed Akt phosphorylation. This evidence suggested that TSA-induced suppression of the PI3K/Akt pathway was more 
A
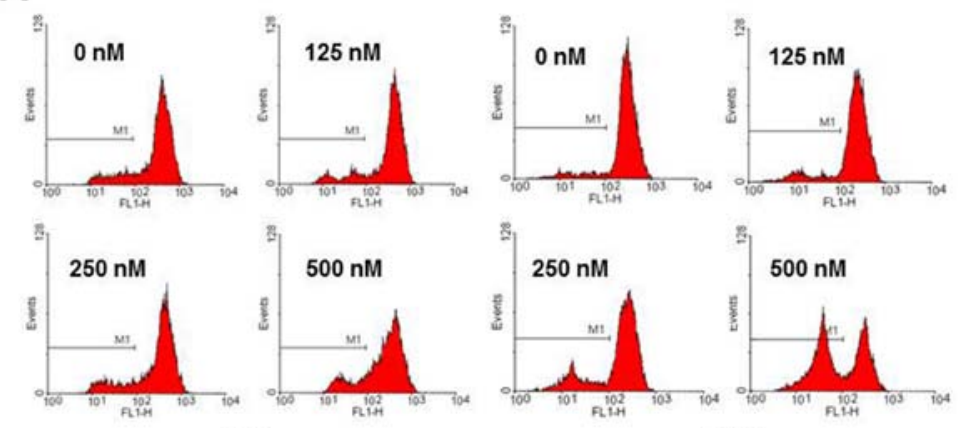

$12 \mathrm{~h}$

$24 \mathrm{~h}$

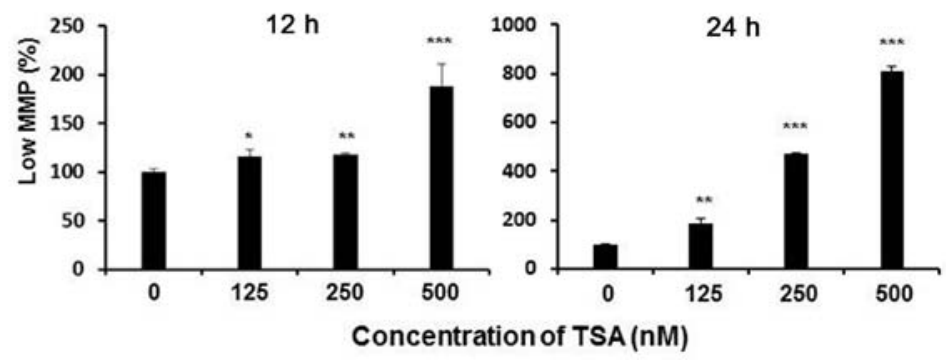

B

\begin{tabular}{|c|c|c|c|c|c|c|c|c|}
\hline \multirow[b]{2}{*}{$\mathrm{TSA}(\mathrm{nM})$} & \multicolumn{4}{|c|}{$12 \mathrm{~h}$} & \multicolumn{4}{|c|}{$24 \mathrm{~h}$} \\
\hline & 0 & 125 & 250 & 500 & 0 & 125 & 250 & 500 \\
\hline $\begin{array}{l}\text { cleaved } \\
\text { caspase-9 }\end{array}$ & - & - & - & - & -- & - & $\longrightarrow$ & \\
\hline a-tubulin & & & & & & & & \\
\hline
\end{tabular}

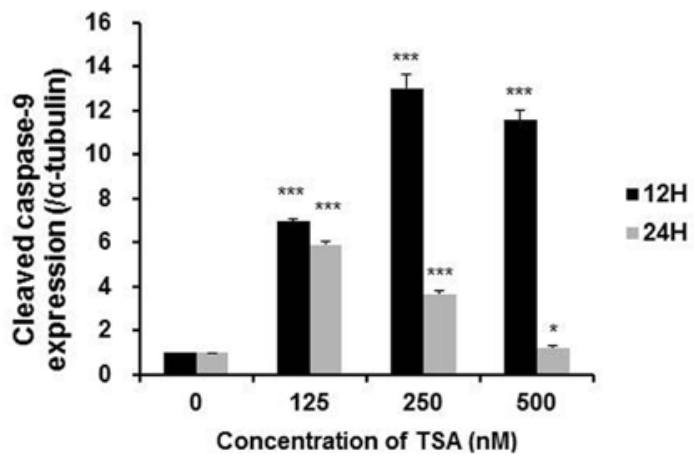

Figure 4. TSA induces apoptotic cell death via the endogenous mitochondrial pathway. (A) TSA-induced dissipation of mitochondrial membrane potential. (B) TSA caused caspase- 9 cleavage; ${ }^{*} \mathrm{p}<0.05,{ }^{* *} \mathrm{p}<0.01,{ }^{* * *} \mathrm{p}<0.001$.

effective at early time points. Moreover, when cells were treated with PI3K inhibitor LY294002 $(10 \mu \mathrm{M})$ alone, pro-apoptotic molecule caspase-9 was also subsequently activated (Fig. 5B), which was consistent with a previous study showing that LY294022 attenuates cell viability in 5,637 cells (28). Given these observations, we suggest that the enhanced apoptosis in 5,637 cells induced by TSA is mediated, at least in part, through the PI3K-Akt pathway.

TSA causes Spl downregulation and suppresses survivin expression in 5,637 cells. Reports have previously noted that TSA suppresses Sp1 binding to the promoter of survivin (BIRC5), which belongs to a member of the inhibitor of apoptosis (IAP) family that inhibits caspase activation thereby leading to induction of apoptosis $(29,30)$. Thus, in the present study, we examined whether TSA affects Sp1 and survivin expression in 5,637 cells. Results from Fig. 6A demonstrated that TSA dose-dependently downregulated Sp1 expression after a 24-h treatment, accompanied by a decrease in the survivin protein level (Fig. 6B). However, to further make clear the essential effect exerted by Sp1, we used mithramycin A, which is a prototypic $\mathrm{Sp} 1$ inhibitor possessing capacity to 
A
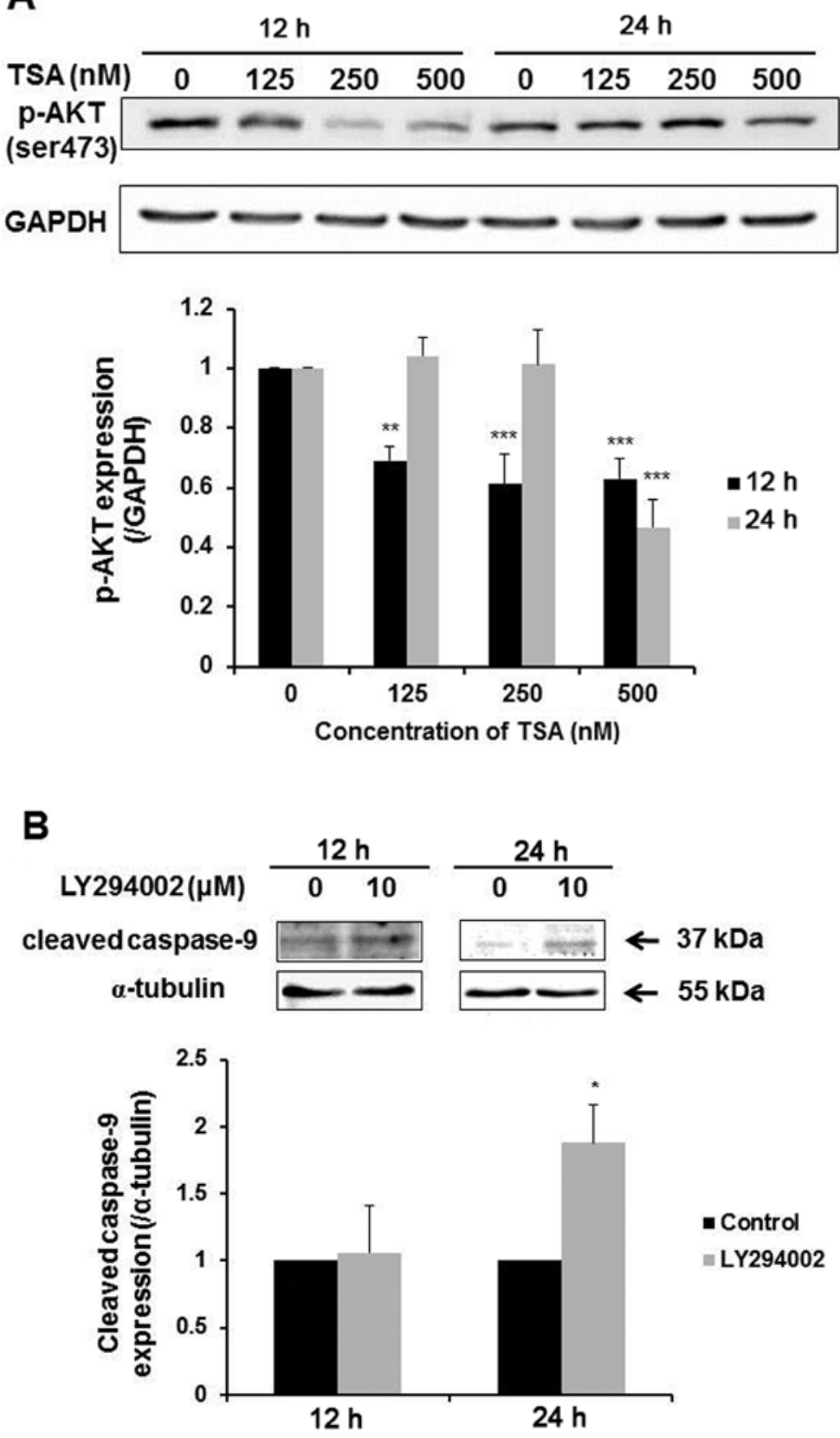

Figure 5. Effect of TSA on the PI3K-Akt signaling pathway in 5,637 cells. (A) TSA inhibited Akt phosphorylation in a time- and dose-dependent manner.(B) PI3K inhibition by LY294002 $(10 \mu \mathrm{M})$ caused caspase-9 activation; ${ }^{*} \mathrm{p}<0.05,{ }^{* *} \mathrm{p}<0.01,{ }^{* * * *} \mathrm{p}<0.001$.

displace Sp1 from its transcription sites (31), to block Sp1 activity. As shown in Fig. 6C, the cell growth was markedly suppressed by treatment of mithramycin A. However, pre-treatment of pan-caspase inhibitor for $1 \mathrm{~h}$ antagonized the influence of mithramycin A and effectively restored the cell viability (Fig. 6D). This evidence indicated that TSA counteracted $\mathrm{Sp} 1$ transcriptional activity, which at least led to downregulation of survivin protein expression following apoptosis at $24 \mathrm{~h}$ in 5,637 cells.

\section{Discussion}

During the past several years, there is growing evidence to suggest that HDAC inhibitors may be applied with favorable outcome in cancer treatment (32). In the present study, we found that HDAC inhibitor TSA caused 5,637 urinary bladder cell death via cell cycle arrest and intrinsic apoptosis (Fig. 7). TSA reduced cell viability (Fig. 1) and caused cell cycle arrest at the G2/M and G1 phases (Fig. 2A), which may result from the increased expression of CDK inhibitor p21 at $12 \mathrm{~h}$ and decreased expression of cyclin D1 that play a pivotal role in cell cycle progression (Fig. 2B). In the classical route, TP53 gene activation increases transcription of p21 mRNA, leading to cell cycle arrest at G1/S and/or G2/M transition (33). However, in 5,637 cells, TP53 was found to bear point mutations at the core domain to affect the ability of p53 to bind DNA (34). Therefore, TSA was likely to induce a p53-independent mechanism to trigger p21 accumulation, similar to a previous study on gemcitabine-induced p21 expression in 5,637 cells (35). Moreover, our current data showed that the $\mathrm{p} 21$ expression 

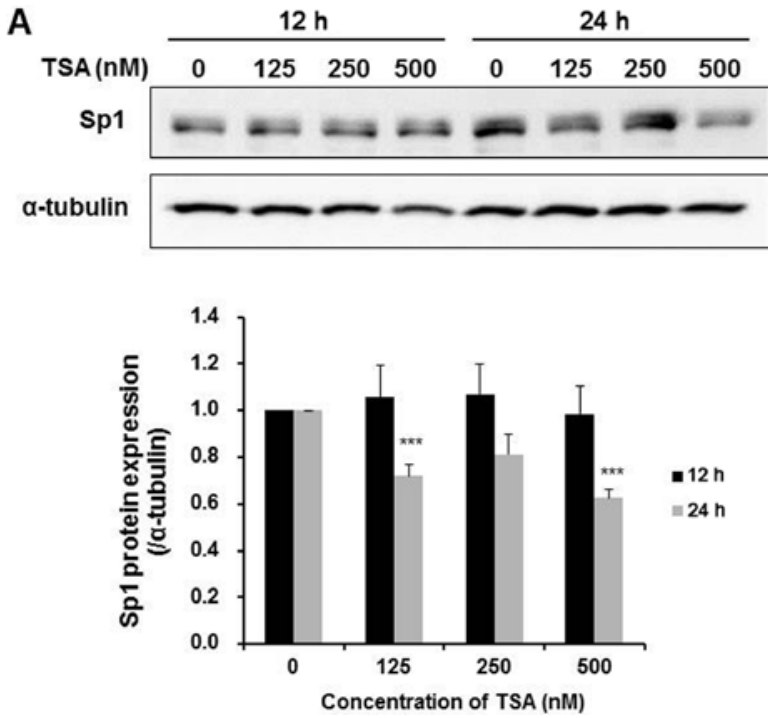

B
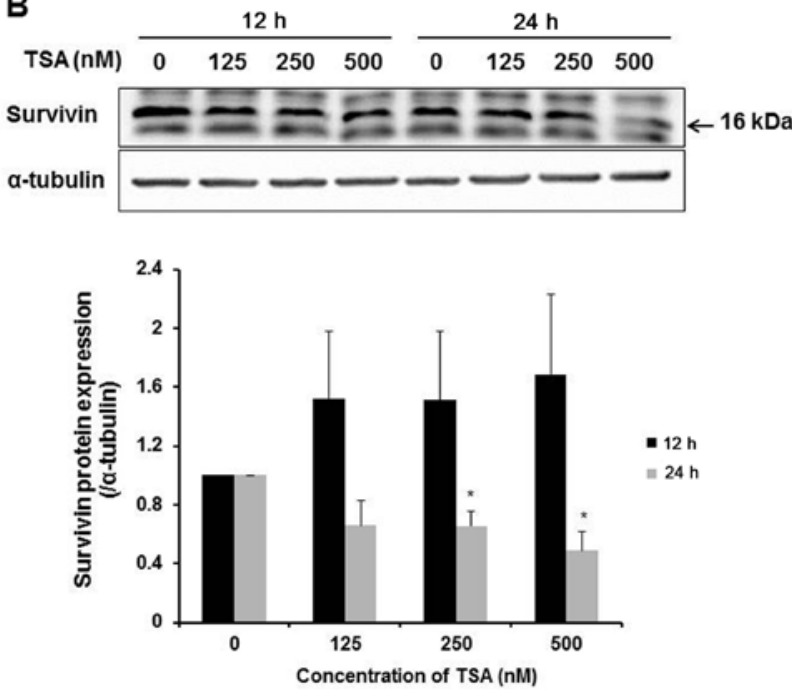
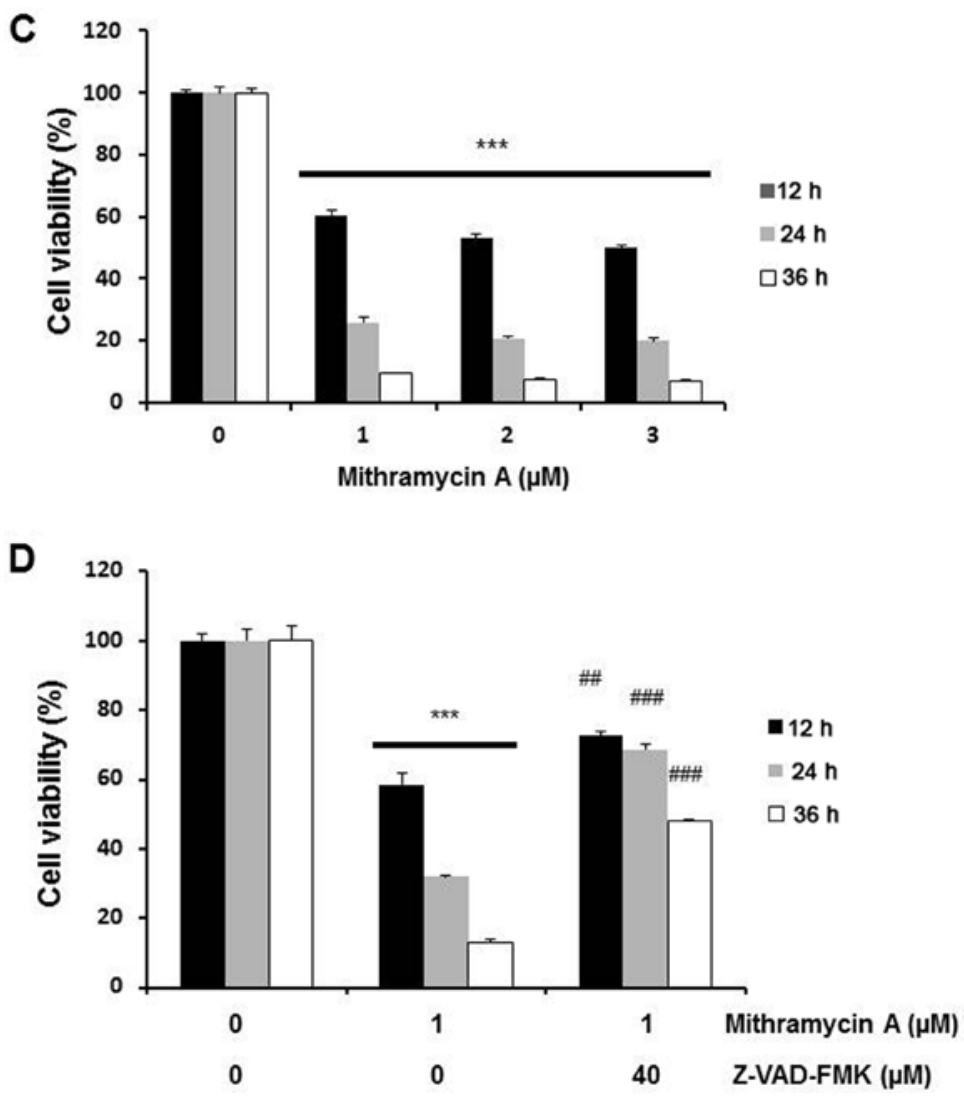

Figure 6. TSA reduces Sp1 and survivin expression after treatment for $24 \mathrm{~h}$. (A) Sp1 protein expression after TSA treatment. (B) Survivin protein expression after TSA treatment. (C) Effect of Sp1 inhibitor mithramycin A on cell viability. (D) Pan-caspase inhibitor Z-VAD-FMK reversed mithramycin A-induced cell death; ${ }^{*} \mathrm{p}<0.05,{ }^{* * *} \mathrm{p}<0.001$ in comparison with the control group; ${ }^{\# \#} \mathrm{p}<0.01,{ }^{\# \# \#} \mathrm{p}<0.001$ in comparison with the group administered mithramycin $\mathrm{A}$ alone.

change was originated by an altered protein level instead of transcriptional regulation since its mRNA amount was unchanged after TSA treatment (Fig. 2C). A wide variety of evidence suggests that $\mathrm{p} 21$ induction could be affected by some forms of regulation (36). In the present study, TSA treatment did not alter p21 mRNA, while it increased p21 protein at $12 \mathrm{~h}$ followed by repressed expression at $24 \mathrm{~h}$, which was most likely due to the change in translation and/or protein degradation. However, the kinetics underlying the TSA-induced expression regulation of the $\mathrm{p} 21$ protein level in 5,637 cells remains obscure; thus, further study is required to elucidate this issue. Different from $\mathrm{p} 21$, TSA was found to reduce cyclin D1 protein expression at both 12 and $24 \mathrm{~h}$ (Fig. 2B). One study provided relevant evidence that TSA induced cyclin D1 degradation in a ubiquitin-dependent $26 \mathrm{~S}$ proteasome pathway (37), which was most likely responsible for cyclin D1 protein reduction in our results. Notably, although cyclin D1 protein decreased both at 12 and 24 h, G1 arrest was observed only at 24 h (Fig. 2A). This circumstance may be attributed to cyclin E which is involved in $\mathrm{G} 1$ to $\mathrm{S}$ phase progression to compensate for 


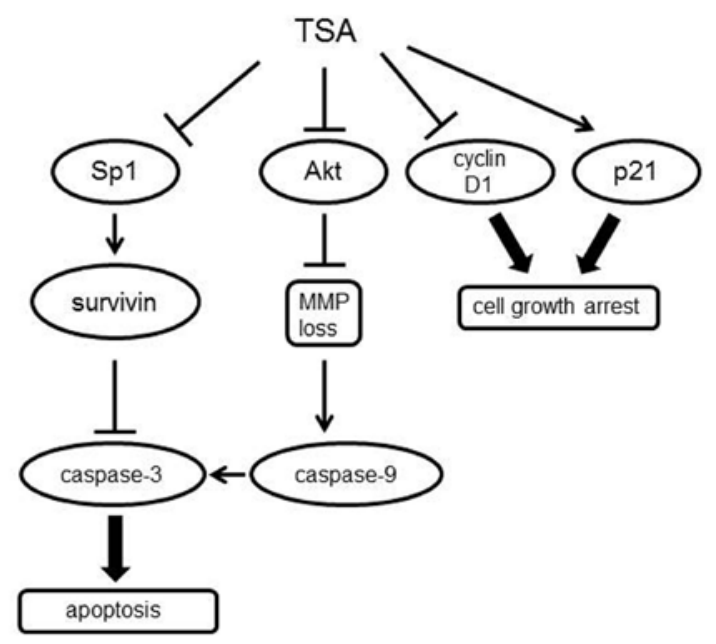

Figure 7. Schematic signaling pathways of TSA-induced cell death in 5,637 cells. TSA caused cell cycle arrest through reduced expression of cyclin D1 and upregulated induction of p21. TSA-induced apoptosis is associated with pAKT inhibition and MMP loss at the early phase, followed by downregulation of Sp1 and survinin at the late phase of treatment.

cyclin D1 loss at the early time point (38). In addition to cell cycle arrest, TSA caused apoptotic cell death characterized by upregulated levels of pro-apoptotic markers such as caspase-3 and cleaved PARP (Fig. 3B), indicating that factors other than p53 signaling could control apoptotic induction in 5,637 cells.

Mitochondria play a crucial role in the intrinsic pathway of apoptosis owing to the release of pro-apoptotic intermediates from the intermembrane space, such as cytochrome $c$, Smac/Diablo and AIF, which in turn amplify the following caspase cascade, leading to the final damage to the cell (39). In this respect, the sustained opening of the mitochondrial permeability transition pore (MPTP) in the mitochondrial inner membrane has been associated with rupture of the outer membrane causing subsequent loss of MMP and release of pro-apoptotic factors (40). In our results, we demonstrated that TSA-induced apoptosis was commensurate with altered MMP (Fig. 4A) as well as subsequent caspase-9 cleavage (Fig. 4B), indicating that TSA induced apoptosis via the mitochondrial pathway in 5,637 cells. However, our results also showed that the induction of 5,637 cell death was closely linked with PI3K/Akt pathway inhibition particularly at $12 \mathrm{~h}$. Akt is known to enhance cell survival through the phosphorylation-dependent inhibition of certain pro-apoptotic pathways. Furthermore, activated Akt has been documented to localize in mitochondria and play important functions concerning energy metabolism and cell survival (41). TSA is known to induce Akt dephosphorylation by disrupting HDAC-protein phosphatase 1 (PP1) complex, consequently leading to inactivation of this kinase route in a PP1-dependent manner (42). In contrast, deregulated MMP has a causative linkage with Akt signaling since dephosphorylated Akt may lose the ability to protect mitochondria from MPTP opening (43), which is well concordant with our current results that TSA caused significant MMP loss (Fig. 4A) and pAKT de-phosphorylation (Fig. 5A), and LY294002 treatment also induced caspase-9 activation (Fig. 5B). These results supported that the signaling of TSA-mediated apoptosis at the early phase in 5,637 cells was correlated to the blockage of the PI3K-Akt pathway.
Our data demonstrated that treatment with the specific Sp1 inhibitor, mithramycin A, led to a marked decrease in cell viability (Fig. 6C), which was restored following pre-treatment with Z-VAD-FMK (Fig. 6D). These features clearly demonstrated that Sp1 plays a pivotal role in the anti-apoptotic regulation of 5,637 cells. Survivin is a small member of the IAP family and is highly expressed in malignant lesions due to the close association with cell cycle transition as well as anti-apoptotic activity commonly coupling to the poor outcomes of cancer therapies (44). Currently, various clinical trials targeting the overexpression of survivin or activation of its related signaling pathways may pave a promising way for cancer intervention $(45,46)$. Published data indicate a role for $\mathrm{Sp} 1$ in regulating survivin gene transcription since numerous Sp1 binding sites exist in the survivin promoter region (47). It is important to note that in our present results, both $\mathrm{Sp} 1$ and survivin protein levels were downregulated at later time points (Fig. 6), indicating that impairment of the Sp1-survivin pathway contributed to, at least in part, the TSA-induced apoptosis in 5,637 cells. It is known that TSA reduces cell viability by recruiting p53 or p63 to counteract the Sp1-survivin cascade $(29,30)$. However, mutated p53 and intrinsically anti-apoptotic isoform of p63 $(\Delta \mathrm{Np} 63 \alpha)$ retained in 5,637 cells (48) could not repress survivin expression and induce apoptosis. Alternatively, given that TSA-mediated Akt dephosphorylation has been reported to activate GSK3 $\beta$ (42) and GSK3 $\beta$-mediated phosphorylation facilitates Sp1 degradation (49), there is a plausible association between deactivated Akt with downstream Sp1 protein degradation as well as correspondingly decreased expression of survivin in 5,637 cells. Meanwhile, the compromised DNA binding ability of Sp1 resulting from the direct TSA-induced acetylation presumably also aided in reduced survivin expression to some extent (50). Collectively, we conclude that TSA exerts multifaceted effects including the regulation of Sp1-survivin expression and then contributes to the tumor-suppressive behavior observed in 5,637 cells.

\section{Acknowledgements}

The present study was supported by grants from the Ministry of Science and Technology MOST104-2320-B-415-001-MY3 of the Republic of China, Taiwan.

\section{References}

1. Stewart BW and Wild C (eds): International Agency for Research on Cancer and World Health Organization: World Cancer Report 2014.

2. Ferlay J, Soerjomataram I, Dikshit R, Eser S, Mathers C, Rebelo M, Parkin DM, Forman D and Bray F: Cancer incidence and mortality worldwide: Sources, methods and major patterns in GLOBOCAN 2012. Int J Cancer 136: E359-E386, 2015.

3. Kaufman DS, Shipley WU and Feldman AS: Bladder cancer. Lancet 374: 239-249, 2009.

4. Avritscher EB, Cooksley CD, Grossman HB, Sabichi AL, Hamblin L, Dinney CP and Elting LS: Clinical model of lifetime cost of treating bladder cancer and associated complications. Urology 68: 549-553, 2006.

5. Ocker M and Schneider-Stock R: Histone deacetylase inhibitors: Signalling towards $\mathrm{p} 21^{\text {cip1/waf1. }}$. Int J Biochem Cell Biol 39: 1367-1374, 2007

6. Hitomi T, Matsuzaki Y, Yokota T, Takaoka Y and Sakai T: p15 ${ }^{\text {INK4b }}$ in HDAC inhibitor-induced growth arrest. FEBS Lett 554: 347-350, 2003. 
7. Rosato RR and Grant S: Histone deacetylase inhibitors: Insights into mechanisms of lethality. Expert Opin Ther Targets 9: $809-824,2005$

8. Batty N, Malouf GG and Issa JP: Histone deacetylase inhibitors as anti-neoplastic agents. Cancer Lett 280: 192-200, 2009.

9. Zhang $\mathbf{J}$ and Zhong Q: Histone deacetylase inhibitors and cell death. Cell Mol Life Sci 71: 3885-3901, 2014.

10. Minucci S and Pelicci PG: Histone deacetylase inhibitors and the promise of epigenetic (and more) treatments for cancer. Nat Rev Cancer 6: 38-51, 2006.

11. Mottamal M, Zheng S, Huang TL and Wang G: Histone deacetylase inhibitors in clinical studies as templates for new anticancer agents. Molecules 20: 3898-3941, 2015.

12. Yoon S and Eom GH: HDAC and HDAC inhibitor: From cancer to cardiovascular diseases. Chonnam Med J 52: 1-11, 2016.

13. Vanhaecke T, Papeleu P, Elaut G and Rogiers V: Trichostatin A-like hydroxamate histone deacetylase inhibitors as therapeutic agents: Toxicological point of view. Curr Med Chem 11: 1629-1643, 2004.

14. Van Beneden K, Mannaerts I, Pauwels M, Van den Branden C and van Grunsven LA: HDAC inhibitors in experimental liver and kidney fibrosis. Fibrogenesis Tissue Repair 6: 1, 2013.

15. Yamashita Y, Shimada M, Harimoto N, Rikimaru T, Shirabe K, Tanaka S and Sugimachi K: Histone deacetylase inhibitor trichostatin A induces cell-cycle arrest/apoptosis and hepatocyte differentiation in human hepatoma cells. Int J Cancer 103 572-576, 2003.

16. Noh EJ, Lim DS, Jeong G and Lee JS: An HDAC inhibitor, trichostatin $A$, induces a delay at $\mathrm{G}_{2} / \mathrm{M}$ transition, slippage of spindle checkpoint, and cell death in a transcription-dependent manner. Biochem Biophys Res Commun 378: 326-331, 2009.

17. Cohen HY, Lavu S, Bitterman KJ, Hekking B, Imahiyerobo TA, Miller C, Frye R, Ploegh H, Kessler BM and Sinclair DA: Acetylation of the $\mathrm{C}$ terminus of $\mathrm{Ku} 70$ by $\mathrm{CBP}$ and PCAF controls Bax-mediated apoptosis. Mol Cell 13: 627-638, 2004.

18. Medina V, Edmonds B, Young GP, James R, Appleton S and Zalewski PD: Induction of caspase-3 protease activity and apoptosis by butyrate and trichostatin A (inhibitors of histone deacetylase): Dependence on protein synthesis and synergy with a mitochondrial/cytochrome $c$-dependent pathway. Cancer Res 57: 3697-3707, 1997.

19. Kim MS, Kwon HJ, Lee YM, Baek JH, Jang JE, Lee SW, Moon EJ, Kim HS, Lee SK, Chung HY, et al: Histone deacetylases induce angiogenesis by negative regulation of tumor suppressor genes. Nat Med 7: 437-443, 2001.

20. Deroanne CF, Bonjean K, Servotte S, Devy L, Colige A, Clausse N, Blacher S, Verdin E, Foidart JM, Nusgens BV, et al Histone deacetylases inhibitors as anti-angiogenic agents altering vascular endothelial growth factor signaling. Oncogene 21 : 427-436, 2002

21. Yoshikawa M, Hishikawa K, Marumo T and Fujita T: Inhibition of histone deacetylase activity suppresses epithelial-to-mesenchymal transition induced by TGF-betal in human renal epithelial cells. J Am Soc Nephrol 18: 58-65, 2007.

22. Liu LT, Chang HC, Chiang LC and Hung WC: Histone deacetylase inhibitor up-regulates RECK to inhibit MMP-2 activation and cancer cell invasion. Cancer Res 63: 3069-3072, 2003

23. West AC and Johnstone RW: New and emerging HDAC inhibitors for cancer treatment. J Clin Invest 124: 30-39, 2014.

24. Xiong Y, Hannon GJ, Zhang H, Casso D, Kobayashi R and Beach D: p21 is a universal inhibitor of cyclin kinases. Nature 366: 701-704, 1993.

25. Kroemer G, Galluzzi L and Brenner C: Mitochondrial membrane permeabilization in cell death. Physiol Rev 87: 99-163, 2007.

26. Park SJ, Kim MJ, Kim HB, Sohn HY, Bae JH, Kang CD and Kim SH: Trichostatin A sensitizes human ovarian cancer cells to TRAIL-induced apoptosis by down-regulation of c-FLIP $\mathrm{L}_{\mathrm{L}}$ via inhibition of EGFR pathway. Biochem Pharmacol 77: 1328-1336, 2009.

27. Chen CS, Weng SC, Tseng PH, Lin HP and Chen CS: Histone acetylation-independent effect of histone deacetylase inhibitors on Akt through the reshuffling of protein phosphatase 1 complexes. J Biol Chem 280: 38879-38887, 2005.

28. Wu JY, Tsai KW, Li YZ, Chang YS, Lai YC, Laio YH, Wu JD and Liu YW: Anti-bladder-tumor effect of baicalein from Scutellaria baicalensis Georgi and its application in vivo. Evid Based Complement Alternat Med 2013: 579751, 2013.

29. Hsu YF, Sheu JR, Lin CH, Yang DS, Hsiao G, Ou G, Chiu PT Huang YH, Kuo WH and Hsu MJ: Trichostatin A and sirtinol suppressed survivin expression through AMPK and p38MAPK in HT29 colon cancer cells. Biochim Biophys Acta 1820 104-115, 2012.
30. Hsu YF, Sheu JR, Hsiao G, Lin CH, Chang TH, Chiu PT, Wang CY and Hsu MJ: p53 in trichostatin A induced C6 glioma cell death. Biochim Biophys Acta 1810: 504-513, 2011.

31. Sleiman SF, Langley BC, Basso M, Berlin J, Xia L, Payappilly JB, Kharel MK, Guo H, Marsh JL, Thompson LM, et al: Mithramycin is a gene-selective $\mathrm{Spl}$ inhibitor that identifies a biological intersection between cancer and neurodegeneration. J Neurosci 31: 6858-6870, 2011.

32. Newbold A, Falkenberg KJ, Prince HM and Johnstone RW: How do tumor cells respond to HDAC inhibition? FEBS J 283: 4032-4046, 2016

33. Jänicke RU, Sohn D, Essmann F and Schulze-Osthoff K: The multiple battles fought by anti-apoptotic p21. Cell Cycle 6: 407-413, 2007.

34. Vinall RL, Ripoll AZ, Wang S, Pan CX and deVere White RW: MiR-34a chemosensitizes bladder cancer cells to cisplatin treatment regardless of $\mathrm{p} 53-\mathrm{Rb}$ pathway status. Int J Cancer 130: 2526-2538, 2012

35. da Silva GN, de Camargo EA and Salvadori DM: Toxicogenomic activity of gemcitabine in two TP53-mutated bladder cancer cell lines: Special focus on cell cycle-related genes. Mol Biol Rep 39: 10373-10382, 2012.

36. Warfel NA and El-Deiry WS: p21WAF1 and tumourigenesis: 20 years after. Curr Opin Oncol 25: 52-58, 2013.

37. Alao JP, Stavropoulou AV, Lam EW, Coombes RC and Vigushin DM: Histone deacetylase inhibitor, trichostatin A induces ubiquitin-dependent cyclin D1 degradation in MCF-7 breast cancer cells. Mol Cancer 5: 8, 2006.

38. Keenan SM, Lents NH and Baldassare JJ: Expression of cyclin E renders cyclin D-CDK4 dispensable for inactivation of the retinoblastoma tumor suppressor protein, activation of E2F, and $\mathrm{G}_{1}-\mathrm{S}$ phase progression. J Biol Chem 279: 5387-5396, 2004.

39. Riedl SJ and Shi Y: Molecular mechanisms of caspase regulation during apoptosis. Nat Rev Mol Cell Biol 5: 897-907, 2004.

40. Rasola A and Bernardi P: The mitochondrial permeability transition pore and its involvement in cell death and in disease pathogenesis. Apoptosis 12: 815-833, 2007.

41. Lim S, Smith KR, Lim ST, Tian R, Lu J and Tan M: Regulation of mitochondrial functions by protein phosphorylation and dephosphorylation. Cell Biosci 6: 25, 2016.

42. Alao JP, Stavropoulou AV, Lam EW and Coombes RC: Role of glycogen synthase kinase 3 beta (GSK3beta) in mediating the cytotoxic effects of the histone deacetylase inhibitor trichostatin A (TSA) in MCF-7 breast cancer cells. Mol Cancer 5: 40, 2006.

43. Miyamoto S, Murphy AN and Brown JH: Akt mediates mitochondrial protection in cardiomyocytes through phosphorylation of mitochondrial hexokinase-II. Cell Death Differ 15: 521-529, 2008.

44. Ambrosini G, Adida C and Altieri DC: A novel anti-apoptosis gene, survivin, expressed in cancer and lymphoma. Nat Med 3: 917-921, 1997.

45. Cheng Q, Ling X, Haller A, Nakahara T, Yamanaka K, Kita A, Koutoku H, Takeuchi M, Brattain MG and Li F: Suppression of survivin promoter activity by YM155 involves disruption of Sp1-DNA interaction in the survivin core promoter. Int J Biochem Mol Biol 3: 179-197, 2012.

46. Glaros TG, Stockwin LH, Mullendore ME, Smith B, Morrison BL and Newton DL: The 'survivin suppressants' NSC 80467 and YM155 induce a DNA damage response. Cancer Chemother Pharmacol 70: 207-212, 2012

47. Li F and Altieri DC: Transcriptional analysis of human survivin gene expression. Biochem J 344: 305-311, 1999.

48. Lee HO, Lee JH, Choi E, Seol JY, Yun Y and Lee H: A dominant negative form of p63 inhibits apoptosis in a p53-independent manner. Biochem Biophys Res Commun 344: 166-172, 2006.

49. Wei S, Chuang HC, Tsai WC, Yang HC, Ho SR, Paterson AJ, Kulp SK and Chen CS: Thiazolidinediones mimic glucose starvation in facilitating Sp1 degradation through the up-regulation of beta-transducin repeat-containing protein. Mol Pharmacol 76: 47-57, 2009.

50. Duan H, Heckman CA and Boxer LM: Histone deacetylase inhibitors down-regulate $b c l-2$ expression and induce apoptosis in $\mathrm{t}(14 ; 18)$ lymphomas. Mol Cell Biol 25: 1608-1619, 2005. 